\title{
Pharmacokinetics, Efficacy, and Safety of a Permeation- Enhanced Testosterone Transdermal System in Comparison with Bi-Weekly Injections of Testosterone Enanthate for the Treatment of Hypogonadal Men*
}

\author{
ADRIAN S. DOBS, A. WAYNE MEIKLE, STEFAN ARVER, STEVEN W. SANDERS, \\ KIM E. CARAMELLI, AND NORMAN A. MAZER \\ Johns Hopkins Medical Center (A.S.D.), Baltimore, Maryland 21287; Departments of Medicine \\ (A.W.M.) and Pharmaceutics (N.A.M.), University of Utah, Salt Lake City, Utah 84132; Karolinska \\ Hospital (S.A.), Stockholm, Sweden; and TheraTech Inc. (S.W.S., K.E.C., N.A.M.), Salt Lake City, \\ Utah 84108
}

\begin{abstract}
The pharmacokinetics, efficacy, and safety of the Androderm testosterone (T) transdermal system (TTD) and intramuscular T enanthate injections (IM) for the treatment of male hypogonadism were compared in a 24-week multicenter, randomized, parallel-group study. Sixty-six adult hypogonadal men (22-65 years of age) were withdrawn from prior IM treatment for 4-6 weeks and then randomly assigned to treatment with TTD (two 2.5-mg systems applied nightly) or IM ( $200 \mathrm{mg}$ injected every 2 weeks); there were 33 patients per group. Twenty-six patients in the TTD group and 32 in the IM group completed the study.

TTD treatment produced circadian variations in the levels of total $\mathrm{T}$, bioavailable $\mathrm{T}$, dihydrotestosterone, and estradiol within the normal physiological ranges. IM treatment produced supraphysiological levels of T, bioavailable $\mathrm{T}$, and estradiol (but not dihydrotestosterone) for several days after each injection. Mean morning sex hormone levels were within the normal range in greater proportions of TTD patients (range, 77-100\%) than IM patients (range, 19-84\%). Both treatments normalized LH levels in approximately $50 \%$ of patients with primary hypogonadism; however, LH levels were suppressed to
\end{abstract}

the subnormal range in $31 \%$ of IM patients $v s .0 \%$ of TTD patients. Both treatments maintained sexual function (assessed by questionnaire and Rigiscan) and mood (Beck Depression Inventory) at the prior treatment levels.

Prostate-specific antigen levels, prostate volumes, and lipid and serum chemistry parameters were comparable in both treatment groups. Transient skin irritation from the patches was reported by $60 \%$ of the TTD patients, but caused only three patients $(9 \%)$ to discontinue treatment. IM treatment produced local reactions in $33 \%$ of patients and was associated with significantly more abnormal hematocrit elevations (43.8\% of patients) compared with TTD treatment ( $15.4 \%$ of patients). Gynecomastia resolved more frequently during TTD treatment (4 of 10 patients) than with IM treatment (1 of 9 patients).

Although both treatments seem to be efficacious for replacing $\mathrm{T}$ in hypogonadal men, the more physiological sex hormone levels and profiles associated with TTD may offer possible advantages over IM in minimizing excessive stimulation of erythropoiesis, preventing/ ameliorating gynecomastia, and not over-suppressing gonadotropins ( J Clin Endocrinol Metab 84: 3469-3478, 1999)
$\mathrm{I}^{\mathrm{s}}$ NTRAMUSCULAR administration of the long-acting testosterone $(\mathrm{T})$ esters enanthate and cypionate has been the most commonly used treatment for male hypogonadism in the United States (1). These formulations are generally administered in doses of 200-300 mg every 2-3 weeks (2). Such treatment is effective in increasing circulating levels of $\mathrm{T}$ and restoring virilization and sexual function. However, intramuscular $\mathrm{T}$ usually produces supraphysiologic levels of $\mathrm{T}$ during the first few days after injection, and low-normal or subphysiological levels toward the end of the 14-21-day dosing period $(2,3)$. Patients may experience fluctuations in libido, sexual per-

Received April 28, 1999. Revision received July 7, 1999. Accepted July 12, 1999.

Address all correspondence and requests for reprints to: Adrian S. Dobs, M.D., M.H.S., Associate Professor and Vice Chair, Department of Medicine, Johns Hopkins University, 1830 East Monument Street, Room 328, Baltimore, Maryland 21205. E-mail: adobs@jhu.edu.

* Funded in part by a grant from TheraTech, Inc., NIH General Clinical Research Center Grants 5-M01-RR-00722 and RR-0003524, Swedish Medical Research Council $(11615,400 / 96)$, and The Swedish Society of Medicine. formance, and mood that are associated with the variation in T levels $(1,4)$. Depot injections can be painful and do not produce the circadian variations in $\mathrm{T}$ levels that have been found in young, healthy men (3).

Recently, several transdermal preparations have become available for the treatment of hypogonadal men (5-7). The Androderm testosterone transdermal system (TTD) (7), designed for application to nonscrotal skin, consists of a central gel-containing reservoir that delivers $\mathrm{T}$ across a permeable microporous membrane and a peripheral adhesive region that affixes the system to the skin. Two studies of the pharmacokinetics of the TTD in hypogonadal men have demonstrated that the nightly application of this system can produce physiological concentrations and normal circadian variation of $\mathrm{T}$ and its metabolites $(8,9)$.

In the present randomized, age-matched, open-label, multicenter study, we compared the pharmacokinetics, efficacy, and safety of the TTD with intramuscular injections of T enanthate (IM) administered biweekly in two parallel groups of hypogonadal men treated for 24 weeks. All patients had 
been receiving intramuscular $\mathrm{T}$ treatment before entering this study. Portions of the pharmacokinetic and safety data from this study have been summarized in two previous review articles $(10,11)$.

\section{Subjects and Methods}

\section{Study design and patient population}

Adult hypogonadal males 20 to 65 years of age who had been receiving IM replacement therapy for at least 3 months were eligible for the study. Exclusion criteria included: a history of prostate cancer or treatment for any carcinoma within the past 2 years; serum prostatespecific antigen (PSA) levels $>3.9 \mathrm{ng} / \mathrm{mL}$; transrectal ultrasound-determined prostate volumes $>50 \mathrm{~mL}$ or postvoid residual volumes $>60$ $\mathrm{mL}$; an unstable or untreated endocrine disorder; clinically significant hyperlipidemia; clinically significant psychiatric disease; or the need for tricyclic antidepressant or antipsychotic therapy. The protocol was approved by the Institutional Review Boards of the participating institutions [Johns Hopkins University, University of Utah, Karolinska Hospital, San Diego Endocrine and Medical Clinic (San Diego, CA), Pharmaco Health Research Center (Austin, TX), and Rush PresbytereanSt. Lukes Medical Center (Chicago, IL)] and written informed consent was obtained from all patients.

During the screening period, prospective patients received up to two injections of their current $\mathrm{T}$ replacement medication (usually $\mathrm{T}$ enanthate, administered biweekly or triweekly). After the last T injection, they entered a 4- to 6-week washout period. At the end of the washout period, patients had to exhibit hypogonadal morning serum $\mathrm{T}$ levels of $\leq 300 \mathrm{ng} / \mathrm{dL}$ (or $\leq 350 \mathrm{ng} / \mathrm{dL}$ for patients with Klinefelter's syndrome). Qualified patients were randomized in an age-matched fashion to treatment with either TTD or IM therapy for 24 weeks. The randomization was done centrally by the sponsor. Patients in the TTD treatment group applied two investigational Androderm systems ( $2.5 \mathrm{mg}$ nominal delivery per patch) to the back, abdomen, thigh, or upper arm each evening and wore them for 24 hours. Patients assigned to IM treatment received $200 \mathrm{mg}$ T enanthate (Delatestryl; BTG Pharmaceuticals, Iselin, NJ) by intramuscular injection every 2 weeks. Dosage adjustments were allowed for both groups if adverse events occurred or morning $\mathrm{T}$ levels were outside the normal range of 306-1031 ng/ dL (9). Three patients in the TTD group had an increase in dosage to $7.5 \mathrm{mg} /$ day (three patches applied nightly), and one patient in the IM group had a decrease in dosage to $100 \mathrm{mg}$ or $150 \mathrm{mg}$ on separate occasions. At the time of the pharmacokinetic evaluation (see below) only two patients (both TTD) had undergone a dosing change. All patients who satisfactorily completed the study were eligible to receive TTD treatment in an open-label extension study that followed the present one.

\section{Pharmacokinetic evaluation}

Steady-state pharmacokinetic profiles of $\mathrm{T}$, bioavailable $\mathrm{T}$ (BT), dihydrotestosterone (DHT), and estradiol $\left(\mathrm{E}_{2}\right)$ over the dosing interval were determined at week 16 for each therapy. In the TTD group, blood samples for hormone analysis were collected at $0,3,6,9,12$, and $24 \mathrm{~h}$ after application of systems. The systems were then removed and were not replaced for $24 \mathrm{~h}$. An additional sample for determination of endogenous baseline hormone levels was obtained in the evening before resuming patch application. Patients who received IM treatment reported to the study site for an injection and collection of a pretreatment (day 0) blood sample. Thereafter, blood samples were collected on days 1, 2, 4, 7, 10, and 14 following injection. All hormone analyses (including gonadotropins; see below) were performed at a central laboratory (Endocrine Sciences, Calabasas Hills, CA) using validated assays and normal ranges that have been described previously (9). Pharmacokinetic parameters included the maximum concentration $\left(\mathrm{C}_{\max }\right)$, minimum concentration $\left(\mathrm{C}_{\min }\right)$, the time-average concentration ( $C_{\text {avg; }}$; equal to the area-under-the-curve divided by the dosing interval), time of maximum concentration $\left(\mathrm{T}_{\max }\right)$, and the percentage of the dosing interval in which the hormone profile remained within the normal range (PTNR).

\section{Efficacy assessments}

Serum sex hormone and gonadotropin levels. Morning serum levels of T, BT $\mathrm{DHT}$, and $\mathrm{E}_{2}$ were measured at weeks 2 (TTD group only), 4, 8, 12, 16, 20 , and 24 of randomized treatment at the midpoint of the dosing interval (approximately 12 hours after TTD application or 7 days after IM injection). Assessment of normalization was based on average levels from week 2 (week 4 for IM) to week 24 . Serum concentrations of LH and FSH were determined at the same intervals as for sex hormones using double antibody radioimmunoassays (9).

Sexual function and mood parameters. Nocturnal erectile activity was assessed objectively using outpatient RigiScan (Dacomed, Minneapolis, $\mathrm{MN}$ ) monitoring at week 16 . Tracings from the penile tip were quantified using the erectile index (12), an integrated measure of the frequency, duration, and rigidity of erections. Subjective assessments of erectile frequency and sexual function were performed using the Davidson Questionnaire (13) at week 20 and the Watts Sexual Function Questionnaire (14) at weeks 4, 8, 12,16,20, and 24. The Beck Depression Inventory (15) was used to evaluate mood at week 24 . Treatment responses were assessed as the change from baseline evaluations made during the prior IM treatment.

\section{Safety assessments}

All adverse events reported or observed during the study were recorded. Local tolerability at TTD application sites and IM injection sites were assessed at each visit. Prostate safety was evaluated by serum PSA, prostate volume, and postvoid residual urine volume (measured by transrectal ultrasound). Assessments were made during prior IM therapy, at week 12 (PSA only), and week 24. Plasma levels of cholesterol, low-density lipoprotein cholesterol, high-density lipoprotein cholesterol (HDL), triglycerides, and the cholesterol to HDL ratio were measured monthly (beginning at week 4 of treatment) at a central laboratory (Dr. Paul Bachorik, Johns Hopkins University). Baseline levels during prior IM therapy were measured at each study center (rather than centrally) and, thus, mean changes during treatment were calculated using week 4 as the reference point. Clinical laboratory evaluations (hematology, serum chemistries) were measured at each study center during the prior IM therapy and every 4 weeks during treatment. Individual patients' hematocrit values were normalized to a standard reference range (40-52\%) based on the reference range at each study center.

\section{Statistical analyses}

$\chi^{2}$ analyses were used to compare the TTD and IM treatment groups with regard to the percentages of patients with average morning levels of $\mathrm{T}, \mathrm{BT}, \mathrm{DHT}$, and $\mathrm{E}_{2}$ within the normal morning ranges. Other pharmacokinetic and efficacy parameters were compared using the MannWhitney test. The percentage of patients with elevated hematocrit values $(>52 \%)$ were compared using Fisher's exact test. All comparisons were two-tailed and based on intention to treat. All other analyses presented, including the comparison of treatment groups during prior IM therapy, were based on descriptive statistics. Statistical analyses were performed using SAS (Version 6.08), Stat View software, BIOPAK for pharmacokinetic data, and Excel for correlation analysis.

\section{Results}

\section{Patient population and disposition}

A total of 66 hypogonadal men between the ages of 22 and 65 years were enrolled in the study (33 per treatment group). Demographic characteristics, hypogonadal diagnostic category, prior IM treatment regimen, and sex hormone levels after washout are summarized in Table 1. The treatment groups were comparable with respect to age, race, weight, and dosing regimens of prior $\mathrm{T}$ therapy at study entry. Mean sex hormone levels were not significantly different after washout $(P>0.10)$, with total T levels of $166 \pm 79$ (SD) and $182 \pm 94 \mathrm{ng} / \mathrm{dL}$ in the TTD group and IM group, respec- 
TABLE 1. Summary of background information for all patients

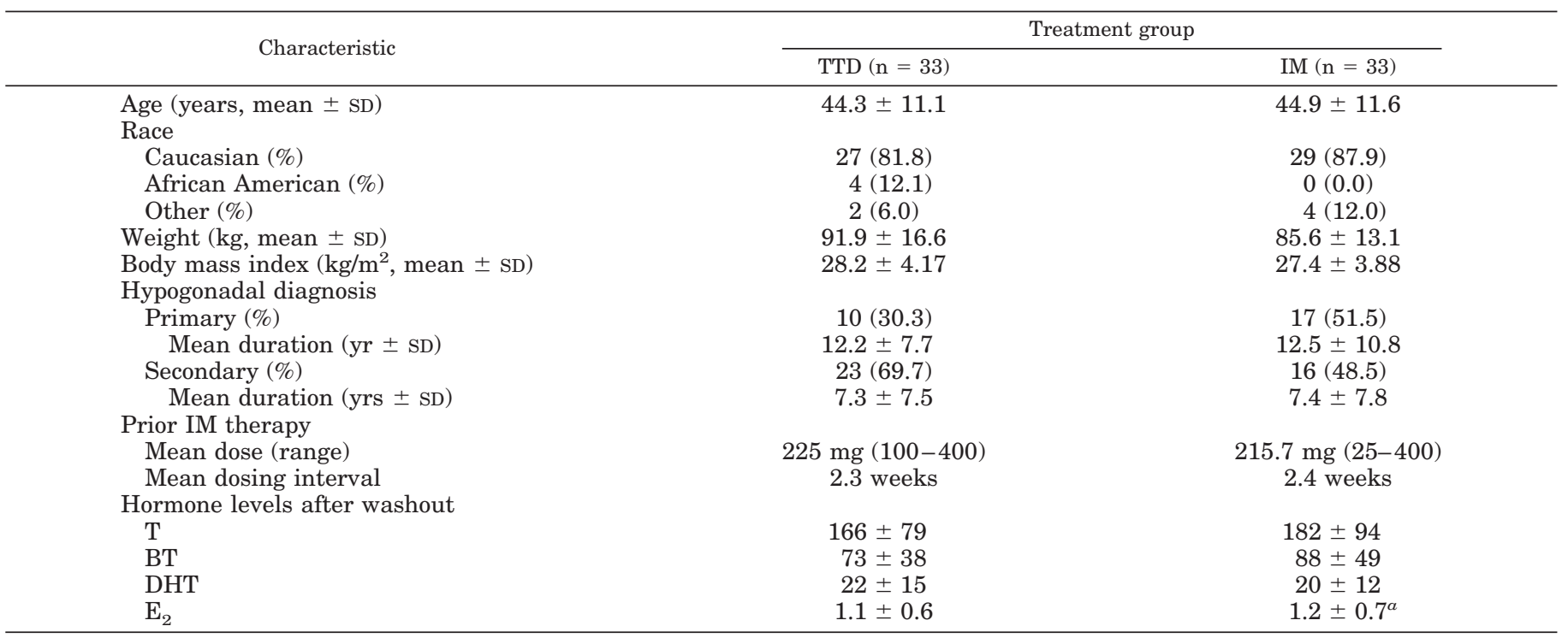

T normal range $(\mathrm{NR})=306-1031 \mathrm{ng} / \mathrm{dL} ; \mathrm{BT} \mathrm{NR}=92-420 \mathrm{ng} / \mathrm{dL} ; \mathrm{DHT} \mathrm{NR}=28-85 \mathrm{ng} / \mathrm{dL} ; \mathrm{E}_{2} \mathrm{NR}=0.9-3.6 \mathrm{ng} / \mathrm{dL}$. $\mathrm{T}_{2}(\mathrm{ng} / \mathrm{dL}): \mathrm{multiply}$ by 0.0347 to convert to $\mathrm{nmol} / \mathrm{L} ; \mathrm{BT}$ (ng/dL): multiply by 0.0347 to convert to $\mathrm{nmol} / \mathrm{L} ; \mathrm{DHT}$ (ng/dL): multiply by 0.0345 to convert to $\mathrm{nmol} / \mathrm{L} ; \mathrm{E}_{2}$ (ng/dL): multiply by 36.71 to convert to $\mathrm{pmol} / \mathrm{L}$.

${ }^{a}$ Number of patients with data at postwashout baseline were $\mathrm{n}=29$ for TTD group.

tively. Mean scores for sexual function parameters and mood assessment during prior IM treatment were similar in the two groups (see baseline values in Table 5).

Four patients in the TTD group and one patient in the IM group withdrew because of adverse events. The adverse events in the TTD group included depression (one patient), allergic contact dermatitis to the TTD (two patients), and local intolerance to the TTD associated with erythema and pruritus (one patient). One IM-treated patient reporting depression, fatigue, edema, weight gain, shortness of breath, joint pain, headaches, and muscular pain withdrew from the study. Three patients in the TTD group withdrew for personal reasons. Overall, 26 patients in the TTD group and 32 patients in the IM group completed the study.

\section{Pharmacokinetic evaluation}

Steady-state pharmacokinetic profiles of the sex hormones were evaluated over a 24-h interval for the TTD group and a 14-day interval for the IM group, starting at week 16. TTD produced mean 24-h serum profiles of T, BT, $\mathrm{DHT}$, and $\mathrm{E}_{2}$ that were within the normal morning reference ranges over the entire 24-h evaluation period (left panels of Fig. 1). Moreover, the T concentrations displayed a circadian variation, with a morning peak and nighttime trough similar to that reported for healthy young men (3). Based on pharmacokinetic analysis of the individual patient profiles (Table 2), the peak T concentration averaged $765 \pm 277 \mathrm{ng} / \mathrm{dL}$ and occurred $8.2 \pm 2.0 \mathrm{~h}$ after TTD application. The mean trough concentration was $280 \pm 146$ $\mathrm{ng} / \mathrm{dL}$. The time-average concentration $\left(\mathrm{C}_{\mathrm{avg}}\right)$ over the 24-h dosing interval was $517 \pm 176 \mathrm{ng} / \mathrm{dL}$.

Mean serum concentrations for T, BT, DHT, and $\mathrm{E}_{2}$ increased sharply after IM injection to levels at or above the upper limit of normal. These values then decreased gradually into the normal range over the 14-day dosing interval (right panels of Fig. 1). Pharmacokinetic analysis of the IM injection profiles (Table 2) showed that peak serum T concentrations averaged $1462 \pm 408 \mathrm{ng} / \mathrm{dL}$ and occurred $2.3 \pm$ 1.9 days after injection. The mean trough concentration was $330 \mathrm{ng} / \mathrm{dL}$, and the time-average concentration over the 14day interval was $815 \pm 167 \mathrm{ng} / \mathrm{dL}$. Hormone normalization during the pharmacokinetic study was assessed in terms of the percentage of the dosing interval in which the hormone profile remained within the normal morning reference range (the parameter PTNR; Table 2). For the TTD regimen, PTNR averaged $81.8 \%$ for $\mathrm{T}, 87.2 \%$ for $\mathrm{BT}, 75.6 \%$ for DHT, and $81.4 \%$ for $\mathrm{E}_{2}$. For the IM regimen, PTNR was significantly lower $(P \leq 0.05)$ for $\mathrm{T}(72.0 \%)$, BT $(38.5 \%)$, and $\mathrm{E}_{2}(34.8 \%)$, but was comparable for DHT (69.6\%). The lower PTNR values during IM treatment reflected the significant portion of time that the BT and $\mathrm{E}_{2}$ profiles were elevated in the supraphysiologic range.

The endogenous baseline hormone levels, assessed in the TTD group by delaying the application of new systems for $24 \mathrm{~h}$ after the pharmacokinetic study (Table 2), were appreciably lower than the morning levels after the washout period from the prior IM treatment (Table 1).

\section{Efficacy assessments}

Morning sex hormone levels. Over the 24-week study period, treatment with TTD systems resulted in mean morning serum levels of T, BT, DHT, and $\mathrm{E}_{2}$ (measured approximately $12 \mathrm{~h}$ after system application) that were within the normal ranges (Table 3). With IM treatment, the mean morning levels of $\mathrm{T}$ and DHT (measured 7 days after injection) were also within the normal range, but the corresponding mean levels of $\mathrm{BT}$ and $\mathrm{E}_{2}$ exceeded the upper 
TTD

IM

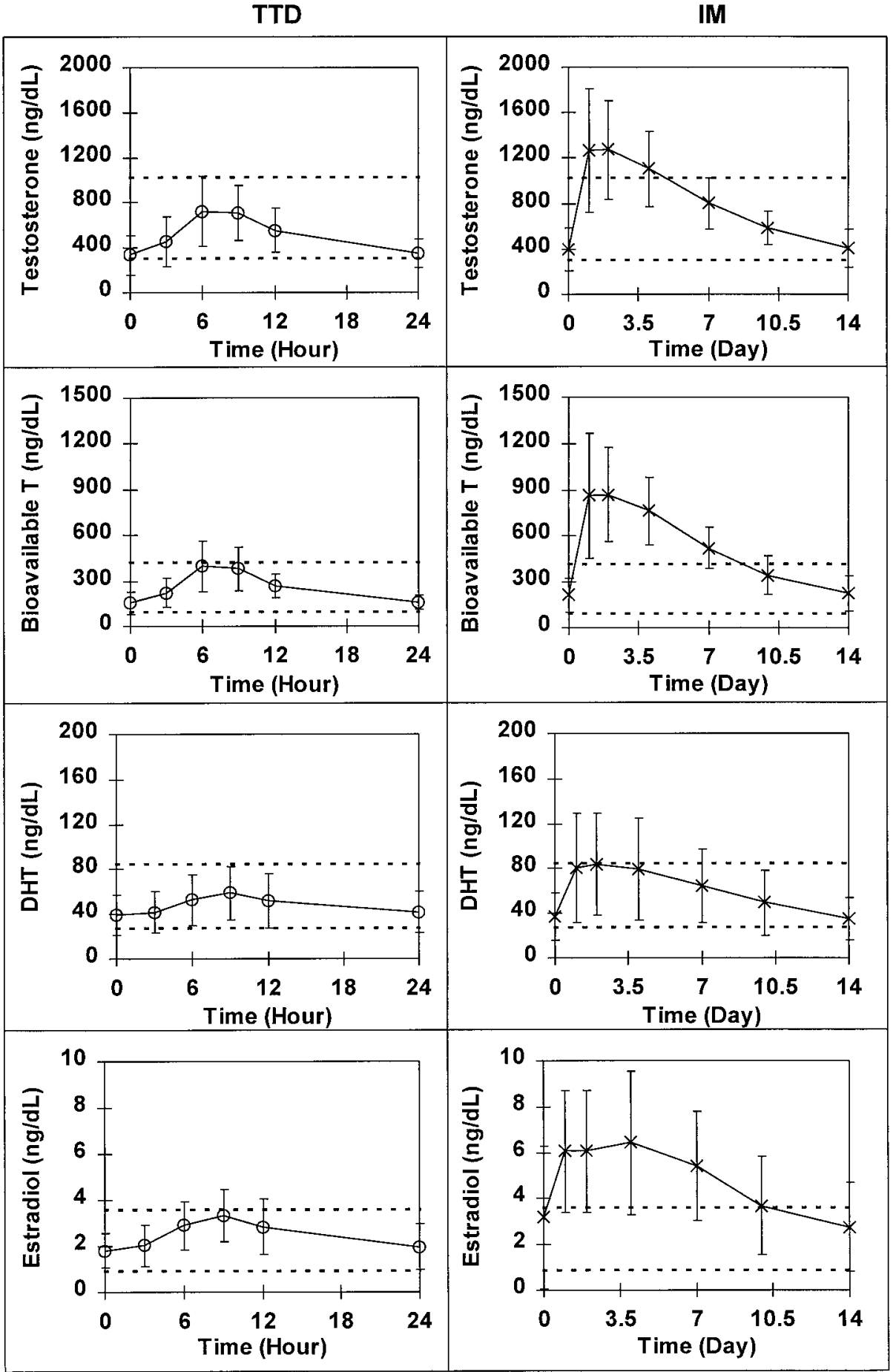

FIG. 1. Steady-state pharmacokinetic profiles of T, BT, DHT, and $\mathrm{E}_{2}$ profiles during nightly applications of TTD systems $(\mathrm{n}=27$; $\bigcirc$, left panels $)$ and biweekly IM injections of $\mathrm{T}$ enanthate ( $\mathrm{n}=29 ; X$, right panels) measured at week 16. Dashed lines denote upper and lower limits of normal range based on morning serum samples ( $\mathrm{T}, 306-1031$ $\mathrm{ng} / \mathrm{dL}$; BT, 92-420 ng/dL; DHT, 28-85 $\left.\mathrm{ng} / \mathrm{dL} ; \mathrm{E}_{2}, 0.9-3.6 \mathrm{ng} / \mathrm{dL}\right)$. Error bars denote \pm SD

limit of normal. The proportion of patients with morning hormone concentrations within the normal range was higher in the TTD group than in the IM group; the differences being highly significant for BT and $\mathrm{E}_{2}(P<$ 0.0001). In comparison with the pharmacokinetic results (Table 2), the morning hormone levels measured in both treatment groups were closer to the time-average concentrations than to the peak levels.
Gonadotropin levels. Table 4 summarizes the LH and FSH levels measured after 24 weeks of treatment in the patient subgroups with primary and secondary hypogonadism. In both subgroups, mean gonadotropin levels were lower in patients receiving IM injections than in those receiving TTD therapy. Of the primary hypogonadal patients in the present study, 50\% in the TTD group had normalized morning LH levels after 24 weeks of treatment and 50\% of patients had elevated LH levels. 
TABLE 2. Summary of pharmacokinetic parameters for sex hormones at week 16

\begin{tabular}{|c|c|c|c|}
\hline \multirow{3}{*}{ Hormone } & \multicolumn{2}{|c|}{ Treatment group } & \multirow{3}{*}{$P$} \\
\hline & TTD & IM & \\
\hline & $\underset{(\mathrm{ng} / \mathrm{dL})}{\operatorname{Mean} \pm \mathrm{SD}}$ & $\underset{(\mathrm{ng} / \mathrm{dL})}{\operatorname{Mean} \pm \mathrm{SD}}$ & \\
\hline \multicolumn{4}{|l|}{$\mathrm{T}$} \\
\hline Number of patients & 27 & 29 & \\
\hline $\mathrm{C}_{\max }^{a}$ & $765 \pm 277$ & $1462 \pm 408$ & \\
\hline $\mathrm{C}_{\text {avg }}$ & $517 \pm 176$ & $815 \pm 167$ & \\
\hline $\mathrm{C}_{\min }$ & $280 \pm 146$ & $330 \pm 141$ & \\
\hline $\mathrm{T}_{\max }$ & $8.2 \pm 2.0 \mathrm{~h}$ & $2.3 \pm 1.9$ days & \\
\hline PTNR & $81.8 \pm 23.0 \%$ & $72.0 \pm 19.8 \%$ & 0.05 \\
\hline BL & $55.4 \pm 62.8$ & N/A & \\
\hline \multicolumn{4}{|l|}{ BT } \\
\hline Number of patients & 27 & 29 & \\
\hline $\mathrm{C}_{\max }$ & $422 \pm 151$ & $1026 \pm 288$ & \\
\hline $\mathrm{C}_{\mathrm{avg}}$ & $257 \pm 74$ & $528 \pm 87$ & \\
\hline $\mathrm{C}_{\min }$ & $126 \pm 54$ & $168 \pm 81$ & \\
\hline $\mathrm{T}_{\max }$ & $7.8 \pm 2.1 \mathrm{~h}$ & $2.3 \pm 1.9$ days & \\
\hline PTNR & $87.2 \pm 12.0 \%$ & $38.5 \pm 14.3 \%$ & $<0.01$ \\
\hline BL & $24.3 \pm 27.4$ & N/A & \\
\hline \multicolumn{4}{|l|}{ DHT } \\
\hline Number of patients & 26 & 29 & \\
\hline $\mathrm{C}_{\max }$ & $60.2 \pm 24.6$ & $95.4 \pm 51.8$ & \\
\hline $\mathrm{C}_{\mathrm{avg}}$ & $48.2 \pm 20.4$ & $61.2 \pm 57.8$ & \\
\hline $\mathrm{C}_{\min }$ & $35.1 \pm 16.5$ & $31.0 \pm 18.8$ & \\
\hline $\mathrm{T}_{\max }$ & $9.8 \pm 3.3 \mathrm{~h}$ & $2.2 \pm 1.3$ days & \\
\hline PTNR & $75.6 \pm 32.2 \%$ & $69.6 \pm 27.0 \%$ & 0.06 \\
\hline BL & $12.3 \pm 10.9$ & N/A & \\
\hline \multicolumn{4}{|l|}{$\mathrm{E}_{2}$} \\
\hline Number of patients & 24 & 26 & \\
\hline $\mathrm{C}_{\max }$ & $3.5 \pm 1.2$ & $7.3 \pm 2.9$ & \\
\hline $\mathrm{C}_{\mathrm{ayg}}$ & $2.5 \pm 0.9$ & $4.8 \pm 2.2$ & \\
\hline $\mathrm{C}_{\min }^{\text {avg }}$ & $1.5 \pm 0.6$ & $2.1 \pm 1.4$ & \\
\hline $\mathrm{T}_{\max }$ & $8.8 \pm 2.3 \mathrm{~h}$ & $2.5 \pm 1.7$ days & \\
\hline PTNR & $81.4 \pm 23.6 \%$ & $34.8 \pm 28.0 \%$ & $<0.01$ \\
\hline $\mathrm{BL}$ & $0.9 \pm 0.5$ & N/A & \\
\hline
\end{tabular}

Pharmacokinetic parameters were measured or derived from the study data for one TTD treatment period $(24 \mathrm{~h})$ and one IM treatment period (14 days).

T normal range $(\mathrm{NR})=306-1031 \mathrm{ng} / \mathrm{dL} ; \mathrm{BT} \mathrm{NR}=92-420 \mathrm{ng} / \mathrm{dL}$; DHT NR $=28-85 \mathrm{ng} / \mathrm{dL} ; \mathrm{E}_{2} \mathrm{NR}=0.9-3.6 \mathrm{ng} / \mathrm{dL} . \mathrm{T}_{2}(\mathrm{ng} / \mathrm{dL}):$ multiply by 0.0347 to convert to $\mathrm{nmol} / \mathrm{L}$; BT (ng/dL): multiply by 0.0347 to convert to $\mathrm{nmol} / \mathrm{L}$; DHT (ng/dL): multiply by 0.0345 to convert to $\mathrm{nmol} / \mathrm{L} ; \mathrm{E}_{2}(\mathrm{ng} / \mathrm{dL})$ : multiply by 36.71 to convert to $\mathrm{pmol} / \mathrm{L}$.

${ }^{a} \mathrm{C}_{\text {max }}$, maximum plasma level; $\mathrm{C}_{\mathrm{avg}}$, time-average plasma level; $\mathrm{C}_{\text {min }}$, minimum plasma level; $\mathrm{T}_{\text {max }}$, occurrence time of $\mathrm{C}_{\max }$ (in hours for TTD and days for IM); PTNR = percentage of time hormone level was within normal range; BL, endogenous baseline level measured in TTD group; N/A, not applicable.

In the IM group, $13 \%$ had elevated levels, $56 \%$ were in the normal range, and $31 \%$ had been suppressed to subnormal levels. Of IM-treated patients with secondary hypogonadism, $56 \%$ had suppressed LH levels, compared with $22 \%$ of TTDtreated patients. FSH levels showed trends similar to LH levels in the patients with primary hypogonadism.

Sexual function and mood parameters. Sexual function parameters assessed during treatment (Erectile Index, Davidson Score, and Watts Score) were comparable with the patients' previous IM treatment regimens, and there were no statistically significant differences between groups (Table 5). No clinically significant change from prior IM therapy to week
24 was observed in the mean Beck Depression Inventory score for either treatment group.

\section{Safety assessments}

Adverse events. Twenty patients treated with TTD $(60.6 \%)$ and 16 patients treated with IM (48.5\%) experienced at least one adverse event during the study. The most common adverse events in the TTD group were pruritus (nine patients, 27.3\%), local skin reactions (six patients, $18.2 \%$ ), and allergic contact dermatitis at the application site (two patients, 6.0\%). Headache also occurred in four patients (12.1\%). In the IM group, the most frequent adverse events were headache (three patients, 9.1\%) and pruritus (one patient, 3.0\%).

Local tolerability. In the TTD group, approximately $60 \%$ of patients experienced mild to moderate erythema or pruritus at an application site at least once during the study. The erythema resolved typically within $24-48 \mathrm{~h}$ after patch removal. Only three patients ( $9 \%)$, however, discontinued treatment due to skin reactions. In the IM group, 33\% of patients experienced at least one local reaction during the study (e.g., pain/soreness, bruising, erythema, swelling, nodules, or furunculosis). No IM-treated patient discontinued for this reason.

Prostate. Prostate evaluations revealed no clinically relevant changes from prior IM therapy in PSA or prostate volume in either treatment group, with the exception of one patient (age 54) in the IM group whose PSA value increased from 5.0 to $12.6 \mathrm{ng} / \mathrm{mL}$ between weeks 12 and 24 of treatment. Despite two normal ultrasound examinations, a biopsy was performed after the study and indicated a microscopic adenocarcinoma of the prostate. Localized prostate adenocarcinoma was also detected in two other patients with normal PSA values, one in the TTD group (age 43) and one in the IM group (age 57), following abnormal prostate ultrasound examinations conducted at the end of the study. All three patients had prostatectomies after the diagnosis was made. In the TTD group, the mean serum PSA values at baseline (during prior IM therapy) and at week 24 were both $0.9 \pm 0.6 \mathrm{ng} / \mathrm{dL}$. In the IM group, mean PSA at baseline (during prior IM therapy) was $0.9 \pm$ $0.7 \mathrm{ng} / \mathrm{dL}$ and at Week 24 was $1.4 \pm 2.2 \mathrm{ng} / \mathrm{mL}$. Mean prostate volumes at the same time points were $21.5 \pm 7.9$ cc and $20.8 \pm 6.8 \mathrm{cc}$ in the TTD group and $22.6 \pm 10.4 \mathrm{cc}$ and $22.7 \pm 8.4 \mathrm{cc}$ in the IM group.

Lipids. From week 4 to week 24 of treatment, HDL levels and cholesterol to HDL ratio remained essentially unchanged in both treatment groups. At week 24, the mean HDL was $49.3 \pm 12.4 \mathrm{mg} / \mathrm{dL}$ for the TTD group and $40.8 \pm 11.2 \mathrm{mg} / \mathrm{dL}$ for the IM group.

Hematocrit. Over the 24-week treatment period, the distribution of individual patient hematocrit values showed potentially clinically important differences between the two treatment groups (Fig. 2). At baseline, 3 of 32 patients in the IM group and 4 of 26 patients in the TTD group had hematocrit values that exceeded $52 \%$. During the treatment period, 14 patients in the IM group (43.8\%) had at least one occurrence of an elevated hematocrit value com- 
TABLE 3. Summary of mean morning sex hormone values ${ }^{a}$ and percentages of patients with hormone values within the normal range $(\% \mathrm{NR})^{b}$

\begin{tabular}{|c|c|c|c|c|c|}
\hline \multirow{3}{*}{ Hormone } & \multicolumn{4}{|c|}{ Treatment group } & \multirow{3}{*}{$P$} \\
\hline & \multicolumn{2}{|c|}{$\mathrm{TTD}^{a}($ mean $\pm \mathrm{SD})$} & \multicolumn{2}{|c|}{$\mathrm{IM}^{a}($ mean $\pm \mathrm{SD})$} & \\
\hline & $\mathrm{ng} / \mathrm{dL}$ & $\% \mathrm{NR}$ & $\mathrm{ng} / \mathrm{dL}$ & $\% \mathrm{NR}$ & \\
\hline $\mathrm{T}$ & $564 \pm 149$ & 96 & $812 \pm 181$ & 84 & 0.14 \\
\hline $\mathrm{BT}$ & $281 \pm 64$ & 100 & $530 \pm 134$ & 19 & 0.0001 \\
\hline DHT & $50 \pm 20$ & 85 & $66 \pm 26$ & 69 & 0.16 \\
\hline $\mathrm{E}_{2}$ & $2.7 \pm 0.9$ & 77 & $5.4 \pm 2.3$ & 25 & 0.0001 \\
\hline
\end{tabular}

${ }^{a}$ Measurements are means of the individual patient averages over weeks 2 through 24 (TTD group, $\mathrm{n}=26$ ) or weeks 4 through 24 (IM group, $\mathrm{n}=32$ ). Samples in the TTD group were obtained approximately $12 \mathrm{~h}$ after application. Samples in the IM group were obtained approximately 7 days after injection.

${ }^{b}$ T NR $=306-1031 \mathrm{ng} / \mathrm{dL} ;$ BT NR $=92-420 \mathrm{ng} / \mathrm{dL} ;$ DHT NR $=28-85 \mathrm{ng} / \mathrm{dL} ; \mathrm{E}_{2} \mathrm{NR}=0.9-3.6 \mathrm{ng} / \mathrm{dL}$. T (ng/dL): multiply by 0.0347 to convert to $\mathrm{nmol} / \mathrm{L}$; BT (ng/dL): multiply by 0.0347 to convert to $\mathrm{nmol} / \mathrm{L}$; DHT (ng/dL): multiply by 0.0345 to convert to $\mathrm{nmol} / \mathrm{L} ; \mathrm{E}_{2}$ (ng/dL): $\mathrm{multiply} \mathrm{by}$ 3.671 to convert to $\mathrm{pmol} / \mathrm{L}$.

TABLE 4. Gonadotropin levels after 24 weeks of treatment and percentages of patients with high, normal, and low range values

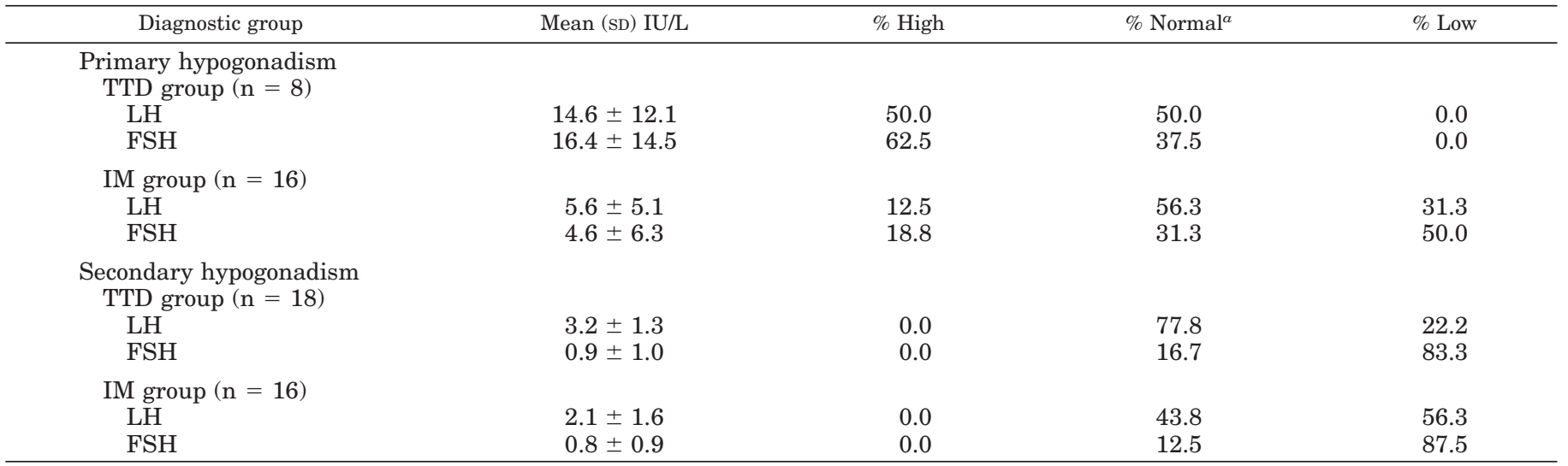

${ }^{a}$ LH normal range, 2.3-13.1 IU/L; FSH normal range, 1.0-9.6 IU/L.

TABLE 5. Sexual function and mood at baseline and change during treatment

\begin{tabular}{lccc}
\hline \multicolumn{1}{c}{ Parameter } & \multicolumn{2}{c}{ Treatment group } & \multirow{2}{*}{$P^{a}$} \\
\cline { 2 - 3 } & $\begin{array}{c}\text { TTD } \\
\text { (mean } \pm \mathrm{SD})\end{array}$ & $\begin{array}{c}\mathrm{IM} \\
\text { (mean } \pm \mathrm{SD})\end{array}$ & \\
\hline $\begin{array}{l}\text { Erectile index (Tip) } \\
\quad \text { Number }\end{array}$ & 25 & 27 & \\
$\quad$ Baseline value & $8.0 \pm 4.7$ & $8.7 \pm 6.2$ & \\
$\quad$ Change (week 16) & $-1.0 \pm 4.3$ & $+1.5 \pm 5.1$ & 0.09 \\
Davidson score & & & \\
$\quad$ (no. erections per 14 days) & & & \\
$\quad$ Number & 20 & 24 & \\
$\quad$ Baseline value & $13.5 \pm 9.4$ & $16.3 \pm 10.0$ & \\
$\quad$ Change (week 20) & $-0.2 \pm 8.4$ & $+2.0 \pm 8.3$ & $>0.10$ \\
Watts score & & & \\
$\quad$ Number & 23 & 26 & \\
$\quad$ Baseline value & $60.4 \pm 7.9$ & $60.3 \pm 8.6$ & \\
$\quad$ Change (week 4-24) & $-1.3 \pm 6.8$ & $+0.9 \pm 4.9$ & $>0.10$ \\
Beck depression inventory & & & \\
$\quad$ Number & 24 & 22 & \\
$\quad$ Baseline value & $4.8 \pm 5.7$ & $4.7 \pm 4.2$ & \\
$\quad$ Change (week 24) & $-0.9 \pm 3.1$ & $+0.2 \pm 4.3$ & $>0.10$ \\
\hline
\end{tabular}

Number values represent numbers of patients with complete data at baseline and at the treatment week when change was evaluated.

${ }^{a}$ Corresponds to the comparison of change values between groups. pared with 4 patients in the TTD group $(15.4 \%)(P=0.025$, two-sided Fisher's exact test). Of the 14 IM patients with hematocrit elevations, average morning levels of T, BT, $\mathrm{DHT}$, and $\mathrm{E}_{2}$ were above the normal range in $3,11,5$, and 12 patients, respectively. Of the four TTD patients with hematocrit elevations, average morning levels of $\mathrm{T}, \mathrm{BT}$, and DHT were normal in all; however, the average morning $\mathrm{E}_{2}$ level was elevated in three patients. Using data from all 58 patients who completed the trial (unstratified by treatment group), hematocrit levels at week 24 were significantly correlated to the average morning levels of BT $(\mathrm{r}=0.46, P<0.001)$ and $\mathrm{E}_{2}(\mathrm{r}=0.58, P<0.001)$ and to age $(\mathrm{r}=0.36, P=0.01)$, but were not significantly correlated to average morning levels of T or DHT $(P>0.05)$ (Fig. 3). Using IM-treated patient data only, hematocrit values correlated significantly with both $\mathrm{E}_{2}(\mathrm{r}=0.52, P<0.005)$ and age $(\mathrm{r}=0.41, P=0.02)$. For the TTD-treated patients, hematocrit values correlated significantly with BT $(\mathrm{r}=$ $0.40, P<0.05)$ and $\mathrm{E}_{2}(\mathrm{r}=0.50, P<0.01)$.

Serum chemistry. No clinically relevant changes in serum chemistries in either treatment group were observed.

Gynecomastia. At the start of the study, gynecomastia was present in 10 patients randomized to the TTD group and 9 

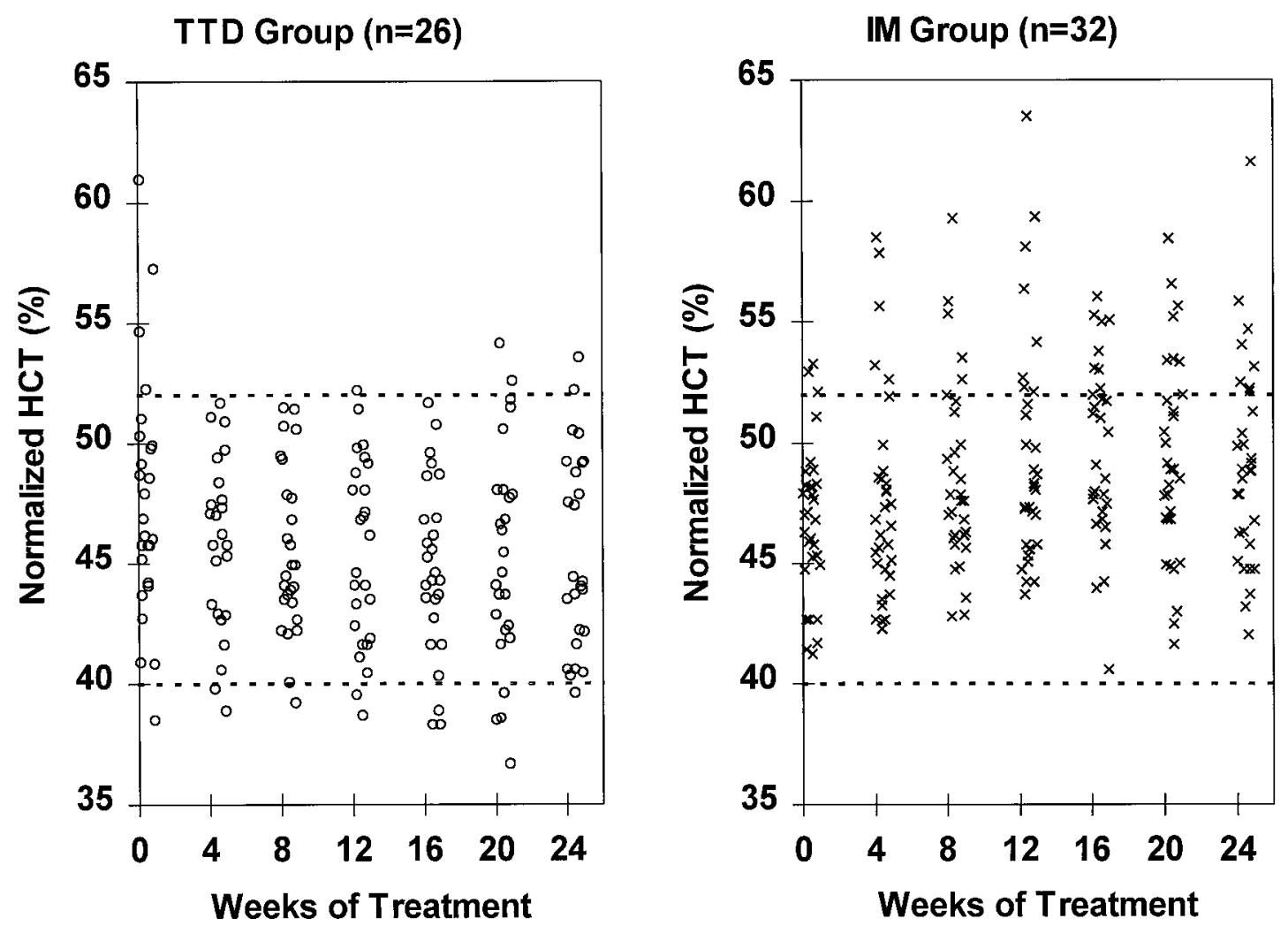

FIG. 2. Individual hematocrit values measured monthly during 24 weeks of treatment in the TTD group $(\mathrm{n}=26$; $\bigcirc$, left panel) and IM group $(\mathrm{n}=32 ; X$, right panel). Values at 0 weeks of treatment correspond to screen values obtained during prior IM therapy. Dashed lines denote upper and lower limits of normal range $40-52 \%$. Abscissa's of data points incorporate small random variation to separate overlapping values.

patients randomized to the IM group. In the TTD group, gynecomastia resolved in three patients, improved in one patient, and developed in another patient. In the IM group, gynecomastia resolved in only one patient and was unchanged in the remaining eight patients.

\section{Discussion}

In the current study, therapy with TTD produced mean morning $\mathrm{T}$ levels that were within the normal range in $96 \%$ of patients, whereas mean morning BT, DHT, and $\mathrm{E}_{2}$ levels were within the normal ranges in $100 \%, 85 \%$, and $77 \%$ of patients, respectively, throughout the 24 -week study. These results are consistent with those reported in an earlier longterm study of TTD therapy by Arver et al. (16). In contrast, IM therapy produced sex hormone levels that were more often outside (above) normal reference ranges. This was especially notable in the case of mean morning BT and $E_{2}$ levels measured 7 days after injection, which were in the normal range for only $19 \%$ and $25 \%$ of IM-treated patients, respectively.

The current study also provided detailed pharmacokinetic information on the steady-state profiles of $\mathrm{T}, \mathrm{BT}$, $\mathrm{DHT}$, and $\mathrm{E}_{2}$ during the respective dosing intervals for the TTD and IM injection regimens. For TTD, the results were consistent with earlier studies $(8,16)$ that showed that the nightly application of two TTD systems resulted in morning peaks and evening nadirs similar to the circadian profiles observed in healthy young men (3). BT, DHT, and $\mathrm{E}_{2}$ profiles generally paralleled the $\mathrm{T}$ profiles obtained with TTD, consistent with the results of single-dose pharmacokinetic studies (9). Biweekly IM treatment with $200 \mathrm{mg}$ $\mathrm{T}$ enanthate produced fluctuation in $\mathrm{T}$ levels between the supraphysiological and low-normal range, consistent with other pharmacokinetic studies of this regimen $(2,17,18)$. BT levels showed an even greater degree of fluctuation into the supraphysiological range, reaching average peak levels that were more than twice the upper limit of normal, presumably due to the saturable binding of $\mathrm{T}$ to SHBG, which results in a relative excess of non-SHBG-bound $\mathrm{T}$ (e.g., BT). Whereas DHT levels showed modest fluctuation with IM injections, $E_{2}$ levels showed marked and prolonged increases into the supraphysiological range. The enhancement of $E_{2}$ formation could be due to a preferential uptake of the $\mathrm{T}$ enanthate itself into adipose tissue (including that located intramuscularly at the injection site), where it is aromatized into $\mathrm{E}_{2}$ enanthate and slowly deesterified and released as circulating $\mathrm{E}_{2}$.

The two treatments differed in their effects on LH levels. Although approximately half of the patients with primary hypogonadism attained LH levels in the normal range, $\mathrm{LH}$ levels remained elevated in the remaining TTD patients with primary hypogonadism but were suppressed below the normal range in $31 \%$ of patients treated with IM. Because all TTD patients had achieved BT levels within the normal range, the persistence of elevated LH levels is of unclear significance and may indicate an androgen-resis- 

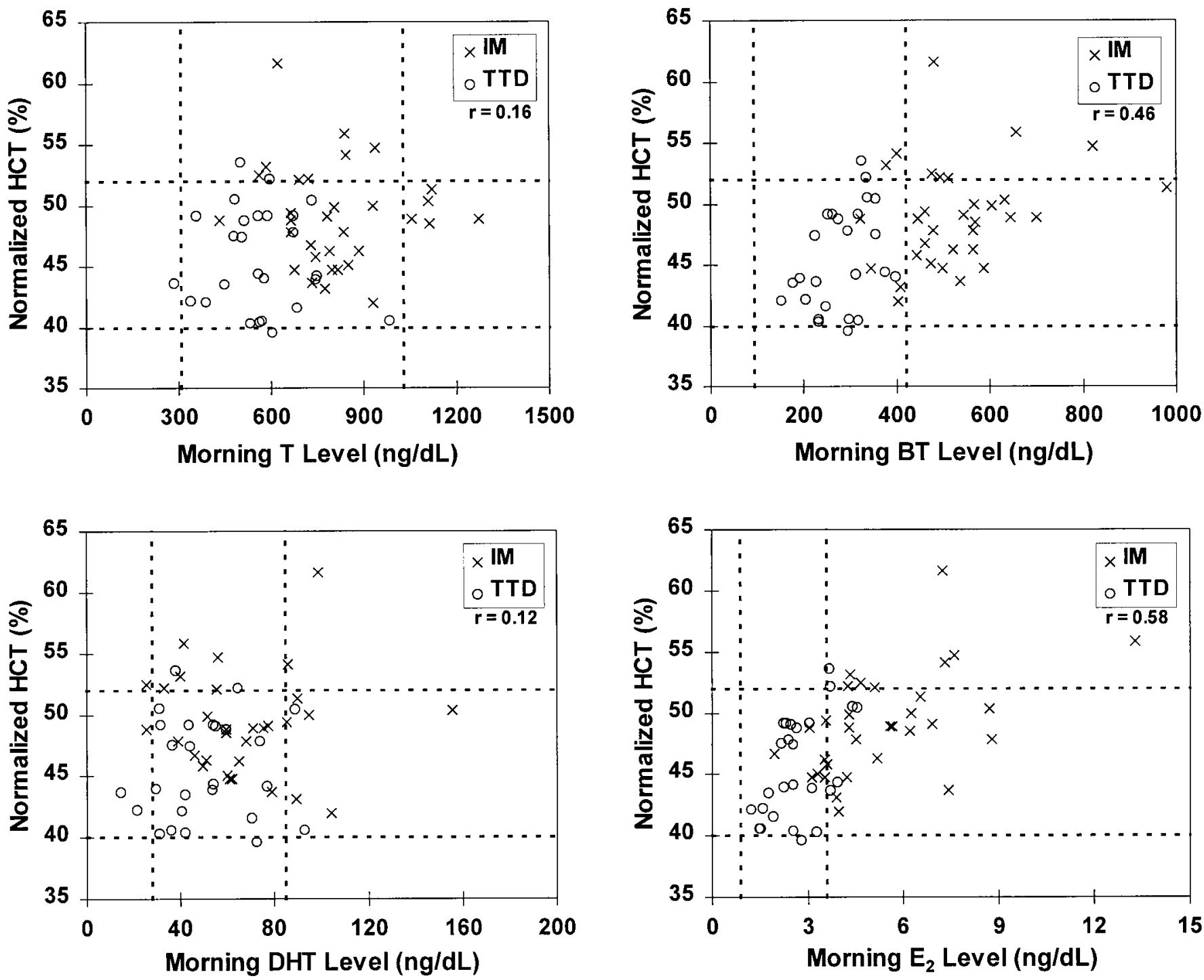

FIG. 3. Correlation of hematocrit values measured after 24 weeks of treatment with TTD $(\mathrm{n}=26$; $\bigcirc)$ and IM ( $\mathrm{n}=32 ; X)$ with average morning hormone levels of T (top left panel), BT (top right panel), DHT (bottom left panel), and $\mathrm{E}_{2}$ (bottom right panel). Dashed horizontal lines indicate the normal range for hematocrit. Dashed vertical lines indicate the normal range for morning hormone levels. $(r=$ correlation coefficient for all patients combined).

tant state at the pituitary and/or hypothalamic levels. Raising the TTD dosage rate from e.g., 5 to $7.5 \mathrm{mg} /$ day could conceivably have normalized LH, but at the expense of supraphysiological BT levels in some patients. The suppression of LH levels below the normal range in the IM group may have resulted from the supraphysiological levels of BT and $E_{2}$ produced by this treatment. Circulating levels of $\mathrm{T}$ (presumably BT) and $\mathrm{E}_{2}$ are both known to exert negative feedback on gonadotropin secretion in men (19, 20). Although the biweekly regimen of $200 \mathrm{mg}$ T enanthate was empirically based on its ability to lower LH in patients with primary hypogonadism (2), the suppression of LH to subnormal levels in about one third of our patients is a nonphysiological effect of this regimen and suggests overreplacement. Lowering the IM dose or increasing the interval between injections could be considered in such patients.
In comparison with the $5 \mathrm{mg} /$ day $\mathrm{T}$ dosing achieved with the TTD, the biweekly administration of $200 \mathrm{mg} \mathrm{T}$ enanthate corresponds to a calculated time-averaged dose of $10.3 \mathrm{mg}$ of unesterified $\mathrm{T}$ per day. This calculated dose exceeds the daily $\mathrm{T}$ production of most healthy young men $(3,8)$. Although the actual delivered dose of unesterified $\mathrm{T}$ varies daily during the IM dosing interval, the timeaveraged BT levels observed with the IM regimen were approximately 2-fold greater than the time-averaged BT levels for TTD (Table 2), consistent with the calculated and nominal daily doses of the corresponding regimens. Despite the different amounts of T delivered, both treatments maintained sexual function and mood at the prior treatment levels, as demonstrated by objective (Rigiscan) and subjective assessments during the study. These findings are consistent with those of the earlier study of TTD therapy in hypogonadal men (12). It should be noted, however, 
that because patients were aware of the type of treatment they received some bias in the subjective assessment was possible.

Although the examiners were also not blind to treatment, gynecomastia was observed to resolve more frequently in the TTD group than in the IM group, a finding consistent with the prior study of Arver et al. (16). Gynecomastia has been postulated to occur as a result of high levels of $E_{2}$ relative to those of $\mathrm{T}$, although this has not been conclusively shown $(1,21)$. The fewer cases of gynecomastia that persisted in the TTD group may be due to the lower concentrations of $E_{2}$ associated with TTD therapy.

Whereas the erythropoietic-stimulating effect of androgens $(22,23)$ has been used to treat a variety of anemias (24), administration of $\mathrm{T}$ has also been reported to cause polycythemia in some patients, particularly those $>50$ years of age (25-27). By increasing blood viscosity, polycythemia reduces cerebral blood flow and poses an additional risk factor for stroke in patients with underlying cardiovascular disease (25). In the present study, the percentage of patients who had at least one supraphysiological hematocrit elevation was nearly 3-fold higher in the IM injection group compared with the TTD group. This finding seems related to the significantly greater percentage of supraphysiological BT and $E_{2}$ levels produced by the IM regimen compared with TTD. The statistical association between hematocrit and $E_{2}$ levels in both treatment groups, which was stronger than the correlation to the patients' age, has not been reported previously and deserves further investigation. Although none of the patients in the present study with elevated hematocrits experienced any thromboembolic events, such concerns regarding have been raised in other studies $(1,25,27,28)$. Periodic monitoring of hematocrit is, therefore, recommended for patients receiving $\mathrm{T}$ replacement therapy (29).

Both TTD and IM treatments were well tolerated by most patients and were not associated with clinically significant elevations in liver enzymes or changes in lipid and prostate parameters. However, end of study PSA and ultrasound evaluations led to the diagnosis of localized prostate cancer in one TTD patient and two IM patients, which were treated surgically. The most frequently reported adverse events with TTD were related to local irritation from the patches, a common finding with transdermal delivery systems (30). Recent clinical studies have shown that applying a small amount of $0.1 \%$ triamcinolone acetonide cream to the skin under the Androderm patch reservoir reduces the incidence and severity of skin irritation and does not significantly alter transdermal absorption $(7,31,32)$.

In conclusion, transdermal T (Androderm) and IM T enanthate both seem to be efficacious and generally well tolerated for replacing $\mathrm{T}$ in hypogonadal men. Although IM T offers the convenience of decreased frequency of administration, the more physiological sex hormone levels and profiles achieved with TTD may offer possible advantages in minimizing excessive stimulation of erythropoiesis, preventing/ameliorating gynecomastia and not over-suppressing gonadotropins.

\section{Acknowledgments}

We acknowledge the clinical collaboration of Drs. Stuart Weiss (San Diego Endocrine and Medical Clinic, Inc., San Diego, CA), Jan Ogletree (Pharmaco Health Research Center, Austin, TX), and Theodore Mazzone (Rush Presbyterean-St. Lukes Medical Center, Chicago, IL). The statistical support of Dr. James E. Higgins (ClinTrials Research Inc., Research Triangle, NC), L. Rajaram (University of South Florida, Tampa, FL), and Ralph DeLapp (SmithKline Beecham Pharmaceuticals, Collegeville, PA) is also appreciated.

\section{References}

1. Matsumoto AM. 1994 Hormonal therapy of male hypogonadism. Endocrinol Metab Clin North Am. 23:857-875.

2. Snyder PJ, Lawrence DA. 1980 Treatment of male hypogonadism with testosterone enanthate. J Clin Endocrinol Metab. 51:1335-1339.

3. Mazer NA, Sanders SW, Ebert CD, Meikle AW. 1993 Mimicking the circadian pattern of testosterone and metabolite levels with an enhanced transdermal delivery system. In: Gurny R, Junginger H, Peppas N, eds. Pulsatile Drug Delivery: Current Applications and Future Trends. Stuttgart: Wiss Verl.-Ges.; 73-97.

4. Findlay JC, Place V, Snyder PJ. 1989 Treatment of primary hypogonadism in men by the transdermal administration of testosterone. J Clin Endocrinol Metab. 68:369-373.

5. Cofrancesco J Jr, Whalen JJ 3rd, Dobs AS. 1997 Testosterone replacement treatment options for HIV-infected men. J Acquir Immune Defic Syndr Hum Retrovirol 16(4):254-265.

6. ALZA Pharmaceuticals. 1999 Testoderm ${ }^{\circledR}$, Testoderm ${ }^{\circledR}$ with Adhesive, CIII. Physicians Desk Reference, ed 53. Montvale, NJ: Medical Economics Co. 517-520.

7. SmithKline Beecham Pharmaceuticals. 1999 Androderm ${ }^{\circledR}$ CIII. Physicians Desk Reference, ed 53. Montvale, NJ: Medical Economics Co.; 3025-3028.

8. Meikle AW, Mazer NA, Moellmer JF, et al. 1992 Enhanced transdermal delivery of testosterone across nonscrotal skin produces physiological concentrations of testosterone and its metabolites in hypogonadal men. J Clin Endocrinol Metab. 74:623-628.

9. Meikle AW, Arver S, Dobs AS, Sanders SW, Rajaram L, Mazer NA. 1996 Pharmacokinetics and metabolism of a permeation-enhanced testosterone transdermal system in hypogonadal men: influence of application siteXA clinical research center study. J Clin Endocrinol Metab. 815:1832-1840.

10. Meikle AW, Arver S, Dobs AS, Sanders SW, Mazer NA. 1995 Androderm $^{\mathrm{TM}}$ : a permeation enhanced non-scrotal testosterone transdermal system for the treatment of male hypogonadism. In: Bhasin S, Gabelnick HL, Spieler JM et al., eds. Pharmacology, Biology and Clinical Applications of Androgens-Current Status and Future Perspectives. New York: Wiley-Liss; 449-457.

11. Meikle AW. 1998 A permeation-enhanced non-scrotal testosterone transdermal system for the treatment of male hypogonadism. In: Nieschlag E, Behre HM, eds. Testosterone: Action, Deficiency, Substitution, ed 2. Berlin: SpringerVerlag; 389-422.

12. Arver S, Dobs AS, Meikle AW, et al. 1996 Improvement in sexual function in testosterone-deficient men treated for one year with a permeation enhanced testosterone transdermal system. J Urol. 155:1604-1608.

13. Davidson JM, Camargo CA, Smith ER. 1979 Effects of androgen on sexual behavior in hypogonadal men. J Clin Endocrinol Metab. 48:955-958.

14. Watts RJ. 1982 Sexual functioning, health beliefs, and compliance with high blood pressure medications. Nursing Res. 31:278-283.

15. Beck AT, Ward CH, Mendelson M, Mock J, Erbaugh J. 1961 An inventory for measuring depression. Arch Gen Psychiatry. 4:561-571.

16. Arver S, Dobs AS, Meikle AW, et al. 1997 Long-term efficacy and safety of a permeation-enhanced testosterone transdermal system in hypogonadal men. Clin Endocrinol. 47:727-737.

17. Sokol RZ, Palacios A, Campfield LA, Saul C, Swerdloff RS. 1982 Comparison of the kinetics of injectable testosterone in eugonadal and hypogonadal men. Fertil Steril. 37:425-430.

18. Behre HM, Nieschlag E. 1998 Comparative pharmacokinetics of testosterone esters. In: Nieschlag E, Behre HM, eds. Testosterone: Action, Deficiency, Substitution, ed 2. Berlin: Springer-Verlag; 329-348.

19. Finkelstein JS, Whitcomb RW, O'Dea LSL, Longcopes C, Schoenfeld DA, Crowley WF. 1991 Sex steroid control of gonadotropin secretion in the human male. I. Effects of testosterone administration in normal and gonadotropin-releasing hormone-deficient men. J Clin Endocrinol Metab. 73:609-620

20. Finkelstein JS, O'Dea LSL, Whitcomb RW, O'Dea LSL, Crowley WF. 1991 Sex steroid control of gonadotropin secretion in the human male. II. Effects of estradiol administration in normal and gonadotropin-releasing hormone-deficient men. J Clin Endocrinol Metab. 73:621-628.

21. Braunstein GD. 1993 Current concepts: gynecomastia. N Engl J Med. 328:490-495. 
22. Shahidi NT. 1973 Androgens and erythropoiesis. N Engl J Med. 289:72.

23. Ammus SS. 1982 The role of androgens in the treatment of hematologic disorders. Adv Intern Med. 34:191.

24. Gooren LJG, Polderman KH. 1990 Safety aspects of androgen therapy. In: Nieschlag E, Behre HM, eds. Testosterone: Action, Deficiency, Substitution. Berlin: Springer-Verlag; 182-203.

25. Krauss DJ, Taub HA, Lantinga LJ, Dunsky MH, Kelly CM. 1991 Risks of blood volume changes in hypogonadal men treated with testosterone enanthate for erectile impotence. J Urol. 146:1566-1570.

26. Tenover JS. 1992 Effects of testosterone supplementation in the aging male. J Clin Endocrinol Metab. 75:1092-1098.

27. Sih R, Morley JE, Kaiser FE, et al. 1997 Testosterone replacement in older hypogonadal men: a 12-month randomized controlled trial. 82(6):1661-1667.
28. Palacios A, Campfield LA, McClure RD, et al. 1983 Effect of testosterone enanthate on hematopoiesis in normal men. Fertil Steril. 40(1):100-104.

29. Bhasin S, Bremmer WJ. 1997 Clinical review 85: emerging issues in androgen replacement therapy. J Clin Endocrinol Metab. 74:75-83.

30. Hogan DJ, Maibach HI. 1990 Adverse dermatologic reactions to transdermal drug delivery systems. J Am Acad Dermatol. 22:811-814.

31. Wilson DE, Kaidbey K, Boike SC, Jorkasky DK. 1998 Use of topical corticosteroid pretreatment to reduce the incidence and severity of skin reactions associated with testosterone transdermal therapy. Clin Ther 20:299-306.

32. Meikle AW, Annand D, Hunter C, et al. 1997 Pre-treatment with a topical corticosteroid cream improves local tolerability and does not significantly alter the pharmacokinetics of the Androderm ${ }^{\circledR}$ testosterone transdermal system in hypogonadal men. Proc 79th Annual Meeting of the Endocrine Society, Minneapolis, MN, 1997, P1-322. 